\title{
Clima Ético nas Organizações: Evidências de Validade de uma Escala de Medida
}

\author{
Patrícia Emanuele da Cruz Dias Ribeiro ${ }^{1}$ \\ Instituto de Psicologia da Universidade de Brasília, Brasília, DF, Brasil \\ Juliana Barreiros Porto \\ Katia Puente-Palacios \\ Departamento de Psicologia Social e do Trabalho da Universidade de Brasília, \\ Brasília, DF, Brasil \\ Marília Mesquita Resende \\ Decanato de Gestão de Pessoas da Universidade de Brasília, Brasília, DF, Brasil
}

\section{Resumo}

Um tipo específico de clima organizacional que tem sido foco da atenção de vários pesquisadores é o clima ético, entendido como percepções compartilhadas pelos trabalhadores sobre prescrições, proscrições e permissões referentes a obrigações morais nas organizações. O modelo teórico mais adotado ultimamente indica a existência de nove arquétipos do clima ético. Para ser mensurado é importante que haja um instrumento capaz de capturar suas particularidades. Este estudo objetivou investigar evidências de validade de uma escala traduzida do inglês para o português e adaptada ao contexto brasileiro. A versão em português, inicialmente com 36 itens, foi aplicada a 159 trabalhadores de diversas organizações, cujos dados foram submetidos a análises fatoriais exploratórias. A melhor solução evidenciou uma estrutura da escala com 19 itens agrupados em três fatores (Benevolência; Princípios e Regras; Independência e Instrumentalismo) com índices de consistência interna adequados e 42,8\% de variância explicada. Assim como em outros estudos com essa medida, tais resultados demonstraram a fragilidade teórica na captura do fenômeno. São necessários mais estudos para identificar a adequação dessa estrutura para avaliar o clima ético em organizações e investigar o seu poder preditivo.

Palavras-chave: Clima ético, clima organizacional, validade de medida.

\section{Ethical Climate within Organizations: Validity Evidence of a Measure's Scale}

\begin{abstract}
A specific type of organizational climate that has been the focus of attention of many researchers is the ethical climate. It is understood as shared perceptions related to prescriptions, proscriptions and permissions concerning moral obligations within organizations. Nowadays, the most adopted theoretical model stresses nine archetypes composing the ethical climate. To be measured it is substantial to have an instrument capable of capturing its particularities. This study aimed to investigate the validity evidence of a scale translated from English to Portuguese and adjusted to Brazilian context. Therefore, the Portuguese version - initially with 36 items - was administered to 159 workers from multiple organizations.
\end{abstract}

Endereço para correspondência: Campus Universitário Darcy Ribeiro, Departamento de Psicologia Social e do Trabalho, Sala AT-013, Instituto Central de Ciências/Sul, Asa Norte, Brasília, DF, Brasil 70910-900. Fone/ Fax: (61) 3107-6828. E-mail: pattyemanuele@gmail.com 
The data was submitted to exploratory factor analysis. The best-reached solution has revealed a scale structure with 19 items clustered into three factors (Benevolence; Principles and rules; Independence and instrumentalism) with suitable internal consistency indices and an explained variance of $42,8 \%$. As it is shown by other studies using this measure, these results evidence the theoretical model's fragility to capture the phenomenon. Further research are needed to identify the adequacy of the structure found in this study in order to evaluate ethical climate within organizations, as well as its predictive power.

Keywords: Ethical climate, organizational climate, measure's validity

\section{Clima Ético en las Organizaciones: Evidencias de la Validez de una Escala de Medición}

\section{Resumen}

Un tipo específico de clima organizacional que ha recibido la atención de investigadores es el clima ético, comprendido como las percepciones compartidas por los trabajadores sobre prescripciones, proscripciones y permisos relacionados a las obligaciones morales en las organizaciones. El modelo teórico más utilizado últimamente postula la existencia de nueve arquetipos y para medirlos es importante disponer de un instrumento capaz de captar sus particularidades. Este estudio objetivó investigar las evidencias de validez de una escala traducida del inglés al portugués y adaptada al contexto brasileño. La versión en portugués, inicialmente con 36 ítems, fue aplicada a 159 trabajadores de varias organizaciones, cuyos datos fueron sometidos a análisis factoriales exploratorias. La solución más apropiada reveló una estructura compuesta por 19 ítems agrupados en tres factores (Benevolencia; Principios y reglas; Independencia e instrumentalismo), con índices adecuados de consistencia interna y $42.8 \%$ de variancia explicada. Así como ha sido demostrado por otros estudios con esa medida, estos resultados revelan la fragilidad teórica del modelo adoptado para capturar el fenómeno. Son necesarios más estudios para identificar la adecuación de esa estructura para medir el clima ético en las organizaciones e investigar su poder predictivo.

Palabras clave: Clima ético, clima organizacional, validez de medida.

A discussão sobre o papel do clima nas organizações de trabalho não é nova, tendo sido abundante na década de 1960 (Schneider, 1983). $\mathrm{Na}$ atualidade o tema continua presente nas discussões dos teóricos da área, que buscam definir o seu papel em relação a diversos resultados pessoais e organizacionais. Tradicionalmente, o clima tem sido compreendido como um atributo da organização, mas que é capturado a partir das percepções dos trabalhadores sobre os comportamentos padrão e estilos de gestão adotados por ela. Autores como Koys e DeCotiis (1991) o definem como fenômeno que se constrói com base na experiência do trabalhador, composto por diversas dimensões, compartilhado pelos membros de uma unidade da organização e que tem a função de orientar e regular os comportamentos individuais de acordo com os padrões determinados pelo ambiente.
Um atributo também discutido quanto ao clima é o fato de apresentar estabilidade, mas não ser estático. Assim, é compreendido enquanto característica da organização que é passível de alteração a partir da adoção de formas diferentes de fazer a gestão. Isso significa dizer que, embora o clima seja entendido como uma propriedade mutável, não é visto como algo instável. Logo, tem a capacidade de influenciar as práticas e resultados organizacionais, grupais e individuais. Desse modo, compreender o clima organizacional é de suma importância para as organizações, pois esse construto se relaciona à satisfação do trabalho, à qualidade de vida no trabalho, a uma otimização do desempenho das organizações e do rendimento no trabalho (Martins, 2008).

Teorizações relativas ao tema, ocorridas nas décadas mais recentes, têm discutido as vantagens de focar em climas específicos em lugar de 
realizar diagnósticos globais. D'Amato e Zijlstra (2008) abordam essa questão mostrando a existência de climas diversos com ênfases diferenciadas, de sorte a identificar, por exemplo, clima de serviço, de segurança, de inovação, só para mencionar alguns. Da mesma forma, Schulte, Ostroff, Shmulyian e Kinicki (2009) destacam a mudança ocorrida nos estudos de clima, nos quais o foco geral sobre o ambiente de trabalho perdeu espaço para um foco mais específico.

Um tipo de clima organizacional que tem despertado a atenção de pesquisadores e gestores é o clima ético, entendido como percepções compartilhadas pelos trabalhadores em relação a prescrições, proscrições e permissões referentes a obrigações morais nas organizações. A abordagem que vem sendo mais amplamente utilizada nos estudos sobre o tema é a proposta por Victor e Cullen (1988). Segundo esses autores, o clima ético possui um papel importante tendo em vista que um dos aspectos que possivelmente formam a base dos outros tipos de clima são os dilemas éticos próprios do contexto organizacional. Por sua vez, a seleção ou escolha frente a tais dilemas seria guiada pela filosofia ética e pelas teorias sobre o comportamento ético. Além disso, o clima ético poderia influenciar as atitudes e os comportamentos relacionados a conteúdos éticos dos membros de uma organização (Treviño, Weaver, \& Reynolds, 2006), funcionando como uma variável contextual de grande relevância para esse tipo de comportamento.
Tendo como base a teoria ética (Fritzche \& Becker, 1984; Williams, 1985), do desenvolvimento moral (Kohbelrg, 1984) e as teorias socioculturais das organizações (Schneider, 1983), Victor e Cullen (1988) defendem que o clima ético está composto por duas dimensões: o critério ético usado para a tomada de decisão e o lócus de análise usado como referente nas decisões (Rego, 2001). O critério ético se refere às três principais classificações da teoria ética: (a) egoísmo, cujo critério é o interesse próprio; (b) benevolência, baseada no interesse comum; e (c) deontologia ou princípio, que enfatiza a aderência ao princípio. Já o lócus de análise remete ao grupo de referência na identificação da origem do raciocínio moral na delimitação e aplicação de critérios éticos em decisões organizacionais. São eles: (a) individual, quando a análise se refere aos interesses pessoais; (b) local, quando a análise recai sobre os interesses do sistema interno à organização, incluindo grupos e equipes; e (c) cosmopolita, quando a análise envolve o sistema social externo à organização.

A partir dessa concepção, os autores apresentam uma tipologia que combina os três critérios éticos com os três loci de análise, resultando em nove quadrantes que eles denominam arquétipos de climas éticos. A representação gráfica desse esquema de arquétipos pode ser observada na Figura 1, a qual fora retirada da fonte original (Victor \& Cullen, 1988, p. 104), com tradução livre do inglês para o português.

\section{LÓCUS DE ANÁLISE}

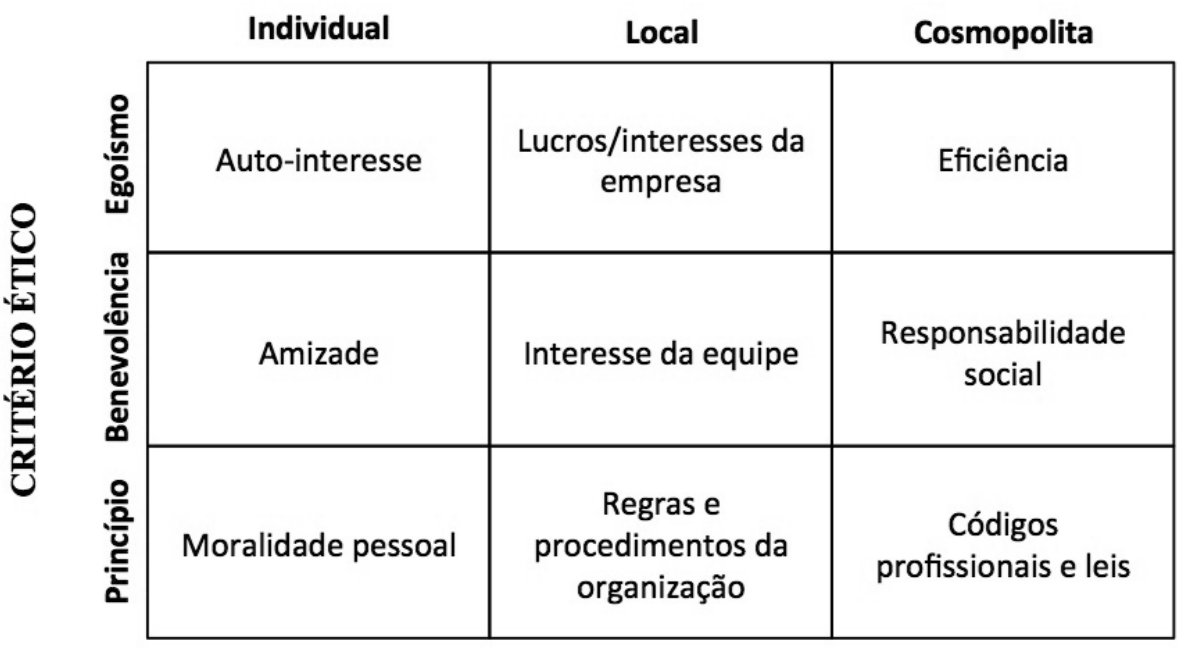

Figura 1. Arquétipos de climas éticos. 
Tendo em vista que o clima é entendido como atributo da organização que é capturado a partir das percepções individuais, é imprescindível que os trabalhadores sejam capazes de identificar padrões característicos de comportamentos reiteradamente presentes na organização. Além disso, essas percepções precisam demonstrar semelhança, uma vez que fazem referência a uma forma característica da organização se comportar. Portanto, devem evidenciar similaridade, de sorte a representar de fato uma propriedade da organização, neste caso, o clima ético dela ou de um setor (Schneider, 1983). Victor e Cullen (1988) encontraram evidências de que as organizações não apresentam um único tipo de clima ético, existindo assim um tipo dominante entre os outros. Tal achado se justifica na possibilidade das organizações apresentarem diferentes configurações, podendo atuar de acordo com diferentes climas éticos.

$\mathrm{Na}$ dinâmica organizacional a questão da ética com que ela opera está sempre presente, e há determinados tipos de clima que evidenciam ações éticas ou não éticas. Mas elas podem ser interpretadas de diferentes formas. Treviño, den Nieuwenboer e Kish-Gephart (2014) salientam que um comportamento ou uma ação organizacional pode estar de acordo com os princípios éticos contidos nas normas e regras da própria organização, mas não necessariamente são éticos na perspectiva de análise cosmopolita. De igual forma, é possível que uma ação seja avaliada como ética com relação ao sistema social externo à organização, mas quando avaliada sob critérios locais, ou seja, com locus de análise no sistema interno à organização, essa mesma ação pode não ser considerada ética.

Em relação às ligações entre clima ético e outros fenômenos existentes na organização, a recente revisão realizada por Treviño et al. (2014) evidencia, mediante resultados de estudos empíricos, diversas variáveis que podem atuar tanto como antecedentes como consequentes de clima ético. No entanto, cabe destacar que o clima ético poderá atuar também como moderador e irá interagir com outras variáveis, como no estudo em que se identificou que, em contextos considerados éticos (como liderança ética e sis- tema de recompensa) a cultura ética teve o maior efeito negativo no comportamento antiético, já quando não era um contexto ético, o clima ético de interesse próprio foi o que mais influenciou o comportamento antiético (Treviño, Butterfiel, \& McCabe, 1998).

Uma das pesquisas aponta que o desenvolvimento moral cognitivo de líderes (Schminke, Ambrose, \& Neubaum, 2005) constitui um dos seus antecedentes. Esse estudo indicou que a congruência entre o nível de desenvolvimento moral de empregados e a percepção do clima ético na organização foi um importante preditor de comprometimento e satisfação no trabalho, sendo negativamente relacionado à intenção de deixar a empresa. Outros autores ainda relacionam o tipo de clima ético com atitudes e comportamentos individuais (Kish-Gephart, Harrison, \& Treviño, 2010; Martin \& Cullen, 2006), incluindo os efeitos do clima ético na redução de comportamentos não éticos no trabalho (Arnaud \& Schminke, 2012) e na tomada de decisão ética (Fritzsche, 2000). Um estudo investigou ainda o efeito do clima ético no comprometimento organizacional (Cullen, Parboteeah, \& Victor, 2003), encontrando que o clima ético de benevolência está associado positivamente à variável critério e o clima egoísta está negativamente relacionado ao comprometimento.

O papel do líder na percepção de clima ético nas organizações tem sido bastante explorado em estudos na área. Erben e Güneser (2007) encontraram evidências de relação entre comportamentos paternalísticos de liderança, clima ético e comprometimento organizacional, tendo o clima um papel mediador entre os outros dois fenômenos. Alguns estudos realizados em diferentes culturas investigaram o impacto dos tipos de clima ético na percepção de práticas éticas de gestores (Deshpande, 1996; Deshpande, George \& Joseph, 2000; Deshpande, Joseph, \& Shu, 2010). Os resultados dessas pesquisas indicaram que há uma predominância de percepções de que gestores bem sucedidos são éticos. Além disso, o estudo mais recente demonstrou que quando o clima de regras é predominante na organização há uma forte relação positiva entre sucesso e comportamento ético. 
Nesse sentido, nota-se, a partir dos resultados apontados nas revisões da área e em meta-análises (Kish-Gephart et al., 2010; Martin \& Cullen, 2006; Simha \& Cullen, 2012; Treviño et al., 2014), que o clima ético se destaca como um importante construto no contexto de trabalho, afetando e interagindo com diferentes atitudes e comportamentos organizacionais, desde comprometimento, satisfação, bem-estar até comportamentos éticos e antiéticos no trabalho. Logo, identificar o clima ético de uma organização pode ser fundamental para uma melhor compreensão do ambiente de trabalho e de como o clima pode incentivar boas práticas e reduzir comportamentos indesejados.

Em relação aos instrumentos adotados para a mensuração do clima ético, teóricos deste campo referenciam, além da escala de Victor e Cullen (1987), uma medida bifatorial (foco em si próprio e foco no outro) a partir da qual foi demonstrada a relevância do papel do clima ético em nível meso organizacional (Arnaud \& Schminke, 2012).

Apesar da acolhida do modelo teórico de Victor e Cullen (1988), evidências empíricas não têm tido êxito em demonstrar os nove arquétipos no instrumento de medida proposto por esses autores - ainda que exista estudo que tenha encontrado suporte para os nove (Peterson, 2002). A maioria dos estudos sobre o tema, realizados utilizando a escala original ou outras dela derivadas, tem evidenciado apenas cinco dos nove tipos de clima ético: clima instrumental ou de interesse próprio, clima de cuidado, clima de independência, clima de regras e clima de leis e códigos (Treviño et al., 2014). Os próprios idealizadores do modelo encontraram, em seus estudos empíricos, apenas esses cinco tipos, nomeados como diligência/zelo (bem-estar compartilhado), regras (adesão e obediência às regras e políticas organizacionais), leis e códigos (adesão e obediência a leis e códigos profissionais), independência (obediência às crenças morais dos indivíduos) e instrumentalismo (satisfação dos interesses próprios).

Discutindo as razões para a não aderência dos fatores da medida às dimensões teóricas do clima ético, Rego (2001) defende que ela se deve a uma falha na delimitação teórica ou metodológica. Assim, ela resultaria do fato dos arquétipos teóricos não serem pertinentes, ou do fato dos instrumentos desenvolvidos até o momento não terem sido capazes de captar adequadamente todos eles. Tendo em vista a literatura revisada, assim como as evidências empíricas sobre o comportamento da medida, é pertinente defender que a segunda opção seja a mais plausível. Isso porque os fundamentos teóricos em que a tipologia de clima ético, resultante da combinação das duas dimensões do modelo, mostra-se bastante consistente. Também é pertinente ponderar se de fato se tratam de nove dimensões independentes ou é de se esperar um número menor de fatores que conjuguem atributos centrais do construto, seja em termos de foco ou de critério.

Dentre as escalas desenvolvidas para investigar o clima ético está o Inventário de Clima Ético (Ethical Climate Index) desenvolvido por Victor e Cullen (1987), a qual já foi atualizada por Cullen, Victor e Bronson (1993). Esta última foi traduzida e adaptada por Rego (2001) para a realidade portuguesa, e em outro estudo foi utilizada para relacionar climas éticos e comportamentos de cidadania organizacional (Rego, 2002).

No contexto brasileiro, grande parte das pesquisas em clima ético nas organizações está embasada no modelo introduzido por Arruda e Navran (2000) e são basicamente investigadas por pesquisadores da administração. O princípio básico do modelo proposto por esses autores está na congruência entre o indivíduo e a organização, ou seja, entre os valores e crenças do trabalhador e as expectativas e exigências da organização. Essas perspectivas e expectativas formariam o clima ético, sendo relatados onze indicadores.

Embora tenha sido confirmado por pesquisas posteriores (Chaves, 2006; Jobim, 2004) e testado em inúmeras empresas, esse modelo não foi inteiramente publicado (Arruda \& Navran, 2000). Cabe ressaltar a carência de refinamento metodológico e de evidências empíricas robustas sobre tal proposição, além do fato de ir de encontro às tendências internacionais de uso do modelo tradicional introduzido por Victor e Cul- 
len (1988), que apresenta suporte empírico de pesquisas posteriores.

Tendo em vista os ajustes realizados à medida original, assim como a inconsistência de resultados encontrados ao investigar as propriedades psicométricas das medidas desenvolvidas para mensurar o clima ético, tomou-se a decisão de investigar empiricamente o comportamento da medida. Para tanto, partiu-se da escala ajustada por Rego (2001). Assim, o objetivo central do estudo foi buscar evidências de validade da escala de clima ético no contexto brasileiro.

\section{Método}

Tendo em vista as teorizações tecidas a respeito do que seja o clima ético, buscou-se verificar empiricamente a pertinência das dimensões constitutivas antes descritas. Os procedimentos adotados para a realização da pesquisa empírica, incluindo especificidades da amostra de respondentes que participaram do estudo, desenho do instrumento, procedimentos e estratégias analíticas de análises de dados, são descritas a seguir.

\section{Amostra}

Para analisar a pertinência do instrumento de medida proposto, foram levantados dados de um total de 159 respondentes. A amostra caracterizou-se pela predominância de pessoas de sexo feminino $(59,1 \%)$, solteiras $(62,4 \%)$, com média de idade de 24 anos $(D P=6,02)$, com nível superior incompleto $(86,2 \%), 70 \%$ oriundos do Distrito Federal e o restante de outros 10 Estados da Federação, 68\% empregados de empresas privadas, com média de tempo de serviço de 2,56 anos $(D P=3,18)$, e renda mensal de 1 a 3 salários mínimos $(54,7 \%)$.

A importância desses dados está no fato do objetivo da pesquisa ser a verificação de evidências de validade da medida. Uma vez que os indícios a serem obtidos estão atrelados à amostra em que a escala sob análise foi aplicada, é de fundamental importância conhecer adequadamente os atributos dos participantes da pesquisa.

\section{Instrumento}

A escala que serviu de ponto de partida para esta pesquisa foi desenvolvida por Victor e Cullen (1987), a mesma que posteriormente foi objeto de revisão em estudo desenvolvido por Rego (2001). A medida proposta pelos autores buscava representar as nove dimensões teóricas consideradas elementos constitutivos do clima. Entretanto, nenhum dos estudos ora referidos evidenciou convergência entre as dimensões teóricas e os fatores empíricos. Assim, considerou-se pertinente realizar uma nova pesquisa buscando realizar ajustes aos itens de sorte a obter maior aderência aos princípios teóricos em que a medida se sustenta.

Para tanto, a primeira tarefa foi traduzir a escala do inglês para a língua portuguesa, utilizando o método back-translation, ou tradução reversa. Depois de cumprida essa etapa, e durante o processo de avaliação por juízes, observou-se a necessidade de realizar alguns ajustes na redação dos itens de forma a torná-los inteligíveis para o público a que se destinava.

O conjunto final de itens a passar pela verificação empírica esteve composto de 36 afirmações. Elas descrevem formas padrão de comportamento da empresa e estão associadas a uma escala de resposta do tipo Likert de verdadeiro/falso de 6 pontos, com extremos que vão de 1 (completamente falsa) a 6 (completamente verdadeira). Além das perguntas do instrumento de clima ético, um conjunto de informações sócio-demográficas e funcionais foram levantadas para a caracterização da amostra.

\section{Procedimentos}

A coleta de dados foi realizada com trabalhadores de diversas organizações. As informações foram levantadas com questionário em papel, visitando os participantes nos seus locais de trabalho ou no momento em que participavam de atividades de capacitação. A participação nesta pesquisa foi voluntária, e foi assegurado o sigilo das respostas e da identidade dos participantes, assegurando desta forma o respeito aos princípios éticos de pesquisa. 


\section{Análise de Dados}

Tendo em vista o objetivo da pesquisa ora relatada, as estratégias analíticas foram as demandadas para desenvolvimento de instrumentos e verificação das suas propriedades psicométricas. Assim, em primeira instância foram realizadas análises fatoriais exploratórias com as quais se buscou identificar uma solução fatorial convergente com a proposta teórica em que a medida se sustenta. A seguir, investigou-se a confiabilidade dos fatores resultantes, mediante o cálculo do Alfa de Cronbach e do valor da média aritmética da correlação item-total. Os resultados encontrados a partir da aplicação dos critérios ora descritos são apresentados na seção a seguir.

\section{Resultados}

O conjunto de dados levantados foi submetido a estratégias de análise fatorial exploratória. Assim, a primeira tarefa consistiu em identificar o padrão geral de respostas. Realizando uma inspeção inicial do banco de dados não foram encontrados dados ausentes sistemáticos ou dados extremos que fragilizassem as análises pretendidas. A seguir, e adotando-se as recomendações de Miles e Shevlin (2001), investigou-se a normalidade da distribuição de todos os itens da medida. Esses autores defendem que valores de assimetria inferiores a 1 (em valores absolutos) demonstram escasso desvio da distribuição empírica da curva normal, logo, seria pertinente ir adiante com as análises pretendidas. Valores de assimetria entre 1 e 2, são descritos pelos autores como evidências de distanciamento da curva normal, mas não representam probabilidade elevada de encontrar resultados atípicos. Por fim, desvios superiores a 2 são descritos como anomalias severas que demandam ajustes, na forma de transformações, nos dados a serem analisados.

Ao analisar a magnitude dos desvios dos itens da escala observaram-se valores entre 0,09 e 1,58 (em valores absolutos). Portanto, dentro dos limites considerados não problemáticos pelos autores. Todavia, segundo Pasquali (2005), a análise fatorial é uma técnica robusta, o que significa dizer que é pouco afetada por valores extremos. Entretanto, se os valores da assime- tria forem severos, a solução fatorial encontrada pode apresentar evidências de validade aceitáveis somente para a amostra da pesquisa e ser inútil para outros cenários organizacionais. Nesse caso a medida não poderia ser utilizada como instrumento de diagnóstico.

Uma vez verificada a distribuição dos dados investigou-se a fatorabilidade da matriz. Para tanto, realizou-se o cálculo do índice de adequação da amostra (KMO), verificou-se a significância do teste de esfericidade de Bartlett e identificou-se a magnitude do determinante da matriz. $\mathrm{O}$ valor do $\mathrm{KMO}$ foi satisfatório tendo revelado um valor de 0,80 ; o teste de esfericidade de Bartlett foi adequado $(p<0,001)$ e o valor do determinante foi baixo e diferente de zero (1,08 E-007).

A seguir, realizou-se a inspeção da matriz de correlações. A respeito do uso desse procedimento, na análise fatorial exploratória, Laros (2005) aponta que se um item não mostrar correlações pelo menos de 0,20 com outros então, provavelmente, revelará um desempenho pobre na mensuração do construto latente. A inspeção da matriz mostrou correlações significativas entre 0,16 e 0,62 , e nenhum item mostrou ausência de correlações significativas com qualquer outro, embora alguns mostrassem valores de baixa magnitude.

$\mathrm{O}$ conjunto de indicadores relativos à fatorabilidade da matriz, ora descritos, mostraram ser pertinente ir adiante com o desafio de buscar reduzir o conjunto de 36 itens a fatores que refletissem a natureza teórica do construto clima ético. Assim, procedeu-se com a etapa de definição do número adequado de fatores a extrair.

Para sustentar a decisão sobre a pertinência do número de fatores que deveria ser retido, adotaram-se critérios como o de Guttman-Kaiser (também chamado de critério de Kaiser), que se sustenta na magnitude dos eigenvalues e mostra o número máximo de fatores tolerado pela matriz de dados; também utilizou-se o critério de Catell relativo a análise visual do gráfico de sedimentação (scree plot) e, paralelamente, buscou-se a observância da natureza teórica do construto. Para a adoção deste último critério tomou-se como norte os achados de Cullen et al. (1993), Rego 
(2001) e Victor e Cullen (1987) nos estudos realizados buscando identificar o arranjo dos itens das medidas propostas ou revisadas por eles.

A aplicação do critério de Kaiser revelou a possibilidade de extrair até 10 fatores. Já o critério gráfico de sedimentação sugeria 5 fatores, e nos estudos anteriores os itens da medida foram agrupados em 3 fatores. Dessa forma, não foi observada unicidade dos critérios, o que demandou a realização de análises diversas em um processo iterativo de busca de soluções psicometricamente ajustadas e teoricamente defensáveis.

Após análise de diversas possibilidades, optou-se por uma solução em três fatores. A extração dos fatores se deu pela utilização do método dos eixos principais (PAF) com rotação Promax, que pressupõe a existência de fatores oblíquos, mas reconhece a sua especificidade. $O$ método de tratamento dos casos ausentes foi o pairwise, pois o tamanho do banco de dados, ao ser de escassa magnitude, não permitia a perda de qualquer dado.

Para que a solução em três fatores seja considerada a mais adequada, houve necessidade de retirada de 17 itens. A sua saída obedeceu a aplicação de critérios como verificação da carga fatorial, complexidade e pertinência teórica. A definição de valor mínimo para a carga fatorial foi realizada seguindo as diretrizes dadas por Tabachnick e Fidell (2001), que alertam quanto ao fato de itens com cargas inferiores a 0,30 oferecerem contribuição pobre para a mensuração do aspecto focado pelo fator. Adicionalmente, foram retirados itens que apresentaram complexidade, o que significa dizer que possuem cargas fatoriais superiores a $0,30 \mathrm{em}$ mais do que um fator e com diferença ente elas inferiores a 0,1 . Por fim, a análise da convergência teórica esteve presente na verificação do atributo da organização que era focado pelo conjunto de itens (fator). Os itens destoantes desse foco foram retirados.

Com a aplicação desses critérios, a solução mais satisfatória reteve 19 itens dos 36 originais e permitiu atingir $42,8 \%$ de variância explicada. O primeiro fator foi denominado de Benevolência e condensa 9 itens. O segundo fator, denominado Princípios e Regras e está composto de 6 itens e, por fim, o terceiro fator, foi denominado Independência e Instrumentalismo e conjuga 4 itens. A tabela a seguir mostra as cargas fatoriais dos itens, a sua organização na matriz bem como os índices de confiabilidade encontrados.

Os dados contidos na Tabela 1 evidenciam a especificidade dos fatores. Assim, o primeiro deles, composto por 9 itens, tem como item mais representativo aquele cujo enunciado descreve o interesse da organização pelo bem dos seus trabalhadores. Os itens constitutivos deste fator apresentam cargas fatoriais entre 0,82 e 0,53 e a retirada de qualquer um deles não traz ganhos em termos de melhor confiabilidade ou adequação teórica. No caso do segundo fator, composto por 6 itens, aquele mais representativo aborda a questão da aderência das pessoas da empresa às normas organizacionais. Neste caso, as cargas fatoriais oscilaram entre 0,71 e 0,48 e não se identificaram evidências de melhora do fator a partir da retirada de qualquer item. Por fim, o terceiro fator, composto por 4 itens, enfatizou a individualidade como característica das políticas e práticas organizacionais. As cargas fatoriais dos itens oscilaram entre 0,65 e 0,57 .

Conforme pode ser observado, os menores valores das cargas fatoriais, para todos os fatores, estiveram acima do que é definido por Tabachnick e Fidell (2001) como contribuição mínima para a manutenção de um item na medida. Também se observaram índices de ajuste satisfatórios e a magnitude da correlação item total revelou uma porcentagem considerável de variância compartilhada pelos conjuntos de itens constitutivos de cada fator. Esses dados foram tomados como indicativos da adequação das decisões tomadas, assim como da aderência da solução à natureza do fenômeno mensurado com a escala. As implicações dos achados, ora descritos, são discutidas na seção seguinte à luz das teorias em que o presente trabalho de pesquisa se sustenta.

\section{Discussão e Considerações Finais}

Os resultados da análise fatorial exploratória reforçam as evidências de que o modelo teórico proposto por Victor e Cullen (1988) não permite capturar a complexidade do fenômeno, uma vez que as análises não apresentam apoio para 
Tabela 1

Cargas Fatoriais da Análise Fatorial Exploratória com Rotação Promax da Medida de Clima Ético

Enunciado do item
Fator 1 Fator 2 Fator 3

1. A preocupação mais importante nesta organização é o bem de todas as pessoas que nela trabalham.

2. A nossa maior preocupação é o bem de todos os que trabalham nesta empresa.

3. Nesta empresa, as pessoas preocupam-se com o bem-estar dos demais.

4. As pessoas preocupam-se muito com o que é globalmente melhor para os empregados.

5. A primeira preocupação nesta organização é o que é bom para cada indivíduo.

6. Nesta empresa, a nossa maior preocupação concentra-se no que é melhor para a outra pessoa.

7. As pessoas dão muita importância ao espírito de equipe.

8. Espera-se que cada pessoa seja bem tratada quando as decisões são tomadas.

9. As pessoas desta empresa têm um forte sentido de responsabilidade perante a comunidade exterior.

10. Espera-se aderência de todas as pessoas às normas e aos procedimentos organizacionais.

11. Espera-se que as pessoas cumpram, acima de tudo, as leis e as normas profissionais.

12. Nesta empresa, espera-se que as pessoas sigam estritamente as normas legais e profissionais.

13. Espera-se que as pessoas façam sempre o que é melhor para os clientes e o público.

14. As pessoas preocupam-se ativamente com os interesses dos clientes e do público.

15. É muito importante seguir estritamente as regras e procedimentos da organização.

16. Nesta organização, cada pessoa, por si própria, decide o que acha correto e incorreto.

17. Nesta empresa, as pessoas guiam-se pela sua própria ética pessoal.

18. Nesta organização, as pessoas protegem, acima de tudo, os seus próprios interesses.

19. O que importa nesta organização é o que cada pessoa considera certo ou errado.

Alfa do fator

Média da correlação Item total

$0,87 \quad 0,78 \quad 0,68$

$0,61 \quad 0,53$

42,80

Total de variância explicada

$\mathbf{0 , 8 2} \quad 0,17 \quad 0,17$

$\mathbf{0 , 7 8} 0,33 \quad 0,03$

$\mathbf{0 , 7 3} 0,24 \quad 0,45$

$\mathbf{0 , 6 9} \quad 0,28-0,01$

$\mathbf{0 , 6 6} \quad 0,17 \quad 0,07$

$\mathbf{0 , 6 4} \quad 0,20 \quad 0,03$

$\mathbf{0 , 5 8} \quad 0,43 \quad-0,20$

$\mathbf{0 , 5 4} 0,42 \quad-0,02$

$\mathbf{0 , 5 3} \quad 0,40 \quad 0,02$

$0,27 \quad \mathbf{0 , 7 1} \quad-0,20$

$0,25 \quad \mathbf{0 , 7 1}-0,15$

$0,29 \quad \mathbf{0 , 7 0} \quad-0,12$

$0,20 \quad \mathbf{0 , 6 1}-0,13$

$\begin{array}{lll}0,30 & \mathbf{0 , 5 9} & -0,10\end{array}$

$0,15 \quad \mathbf{0 , 4 8}-0,09$

$0,05 \quad-0,12 \quad \mathbf{0 , 6 5}$

$0,15 \quad-0,09 \quad \mathbf{0 , 6 1}$

$-0,29 \quad-0,05 \quad \mathbf{0 , 5 7}$

$0,22 \quad-0,23 \quad \mathbf{0 , 5 7}$

0,46

Nota. Cargas fatoriais dos itens que compõem cada fator estão em negrito $(>0,45)$.

a distinção entre nove tipos de clima de ético. Tampouco foram encontradas evidências para os cinco fatores identificados nos estudos de Rego (2001) e de Victor e Cullen. O modelo de nove arquétipos parece não estar alinhado à lógica das organizações ao adotarem princípios éticos. Os limites de cada arquétipo não são fixos, pois fazem parte de um mesmo clima organizacional. São, dessa forma, elementos constitutivos de um mesmo fenômeno, mas não são vistos como componentes estanques, o que justificaria a possibilidade de associações entre esses diversos componentes na estrutura fatorial. Por esta razão também é que optou-se pela rotação Promax na análise fatorial realizada, já que trata-se de uma técnica que parte do princípio de que os fatores são vinculados entre si, mas possuem suas especificidades. 
Por sua vez, os três fatores deste estudo oferecem apoio a dois dos critérios éticos do modelo, quais sejam: benevolência e princípios. $\mathrm{O}$ terceiro fator mescla o terceiro critério de egoísmo com a independência (tipo que envolve princípios com lócus individual). Os itens originalmente desenvolvidos para independência se agruparam com os de egoísmo. Assim, emerge um fator que se pauta na decisão individual para estabelecer o que é certo ou errado e que se aproxima bastante do terceiro critério ético. Dessa forma, é possível afirmar que a escala de clima ético avalia os três critérios éticos que coincidem com as três principais classificações da teoria ética.

Após a realização da análise fatorial do conjunto de 36 afirmações que inicialmente compunham o instrumento, bem como a verificação de evidências de consistência interna, 19 itens foram retidos. A retirada de 17 itens mostrou-se pertinente, tendo em vista que, embora de conteúdo relevante para contemplar teoricamente os nove arquétipos de clima ético, ofereciam contribuições de escassa magnitude para a mensuração do fenômeno em questão, ou foram vistos com pouca clareza ou precisão pelos respondentes. Cabe destacar aqui que é justamente nesse sentido que a análise fatorial exploratória objetiva a identificação de possíveis conjuntos de itens que permitam capturar informações sobre um construto latente, apresentando bons índices de precisão, além de sentido teórico. Assim, a decisão das pesquisadoras por essa solução priorizou a parcimônia e a busca pela captura de maior variância do fenômeno com menos itens.

Estudos futuros precisam identificar a adequação dessa estrutura para avaliar o clima ético em organizações e investigar o seu poder preditivo. Adicionalmente, é preciso testar se esses tipos são compartilhados pelos empregados de organizações para ser caracterizado como clima organizacional. Há também a possibilidade de melhoria dos itens que não foram retidos na análise fatorial realizada neste estudo, no sentido de buscar uma melhor representação dos critérios éticos teoricamente propostos por Victor e Cullen (1988).

\section{Referências}

D’Amato, A., \& Zijlstra, F. R. H. (2008). Psychological climate and individual factors as antecedents of work outcomes. European Journal of Work and Organizational Psychology, 17(1), 33-54. doi:10.1080/13594320701307420

Arnaud, A., \& Schminke, M. (2012). The ethical cimate and the context of organizations: A comprehensive model. Organization Science, 23, 1767-1780. doi:10.1287/orsc.1110.0698

Arruda, M. C. C., \& Navran, F. (2000). Indicadores de clima ético nas empresas. RAE - Revista de Administração de Empresas, 40(3), 26-35. doi:10.1590/S0034-75902000000300004

Chaves, P. S. V. (2006). Clima ético e economia de comunhão: Estudo de caso (Dissertação de mestrado não publicada). Universidade de Fortaleza, CE, Brasil.

Cullen, J. B., Parboteeah, K. P., \& Victor, B. (2003). The effects of ethical climates on organizational commitment: A two-study analysis. Journal of Business Ethics, 46, 127-141.

Cullen, J. B., Victor, B., \& Bronson, J. W. (1993). The ethical climate questionnaire: An assessment of its development and validity. Psychological Reports, 73, 667-674. doi:10.2466/ pr0.1993.73.2.667

Deshpande, S. P. (1996). Ethical climate and the link between success and ethical behavior: An empirical investigation of a non-profit organization. Journal of Business Ethics, 15, 315-320. doi:10.1007/BF00382957

Deshpande, S. P., George, E., \& Joseph, J. (2000). Ethical climates and managerial success in Russian organizations. Journal of Business Ethics, 23, 211-217. doi:10.1023/A:1005943017693

Deshpande, S. P., Joseph, J., \& Shu, X. (2010). Ethical climate and managerial success in China. Journal of Business Ethics, 99, 527-534. doi:10.1007/s10551-010-0666-Z

Erben, G. S., \& Güneser, A. B. (2007). The relationship between paternalistic leadershipand organizational commitment: Investigating the role of climate regarding ethics. Journal of Business Ethics, 82, 955-968. doi:10.1007/s10551-0079605-z

Fritzche, D. J. (2000). Ethical climates and the ethical dimension of decision making. Journal of Business Ethics, 24, 125-140.

Fritzche, D. J., \& Becker, H. (1984). Linking management behavior to ethical philosophy: An empirical investigation. Academy of Management Review, 27, 166-175. 
Jobim, C. M. C. (2004). Clima ético e responsabilidade social: A avaliação dos empregados sobre a relação ética das empresas com os seus stakeholders (Dissertação de mestrado não publicada). Fundação Getúlio Vargas, São Paulo, SP, Brasil.

Kish-Gephart, J. J., Harrison, D. A., \& Treviño, L. K. (2010). Bad apples, bad cases, and bad barrels: Meta-analytic evidence about sources of unethical decisions at work. Journal of Applied Psychology, 95, 1-31. doi:10.1037/a0017103

Koys, D., \& DeCotiis, T. (1991). Inductive measures of psychological climate. Human Relations, 44(3), 265-285.

Kohbelrg, L. (1984). The philosophy of moral development. New York: Harper \& Row.

Laros, J. A. (2005). O uso da analise fatorial: Algumas diretrizes para pesquisadores. In L. Pasquali (Ed.), Análise fatorial para pesquisadores (pp. 163-184). Brasília, DF: Laboratório de Pesquisa em Avaliação e Medida.

Martin, K. D., \& Cullen, J. B. (2006). Continuities and extensions of ethical climate theory: A meta-analytic review. Journal of Business Ethics, 69, 175-194. doi:10.1007/s10551-006-9084-7

Martins, M. C. F. M. (2008). Clima organizacional. In M. M. M. Siqueira (Ed.), Medidas do comportamento organizacional: Ferramentas de diagnóstico e gestão (pp. 29-40). Porto Alegre, RS: Artmed.

Miles, J., \& Shevlin, M. (2001). Applying regression \& correlation: A guide for students and researchers. London: Sage.

Pasquali, L. (2005). Análise fatorial para pesquisadores. Brasília, DF: Laboratório de Pesquisa em Avaliação e Medida.

Peterson, D. K. (2002). The relationship between unethical behavior and the dimensions of the Ethical Climate Questionnaire. Journal of Business Ethics, 41, 313-326. doi:10.1023/ A: 1021243117958

Rego, A. (2001). Climas éticos organizacionais: Validação do constructo a dois níveis de análise. Psicologia: Organizações e Trabalho, 1(1), 69106.

Rego, A. (2002). Climas éticos e comportamento de cidadania organizacional. RAE - Revista de Administração de Empresas, 42(1), 50-63. doi:10.1590/S0034-75902002000100006

Schminke, M., Ambrose, M. L., \& Neubaum, D. O. (2005). The effect of leader moral development on ethical climate and employee atitudes. Organizational Behavior and Human Decision Processes, 97, 135-151. doi:10.1016/j.obhdp.2005.03.006
Schneider, B. (1983). Work climates: An interactionist perspective. In N. W. Feimer \& E. S. Geller (Eds.), Environmental psychology: Directions and perspectives (pp. 106-128). New York: Praeger.

Schulte, M., Ostroff, C. H., Shmulyian, S., \& Kinicki, A. (2009). Organizational climate configurations: Relationships to collective attitudes, customer satisfaction, and financial performance. Journal of Applied Psychology, 94(3), 618-634. doi:10.1037/a0014365

Simha, A., \& Cullen, J. B. (2012). Ethical climates and their effects on organizational outcomes: Implications from past and prophecies for the future. Academy of Management Perspectives, 26, 20-34. doi:10.5465/amp.2011.0156

Tabachnick, B., \& Fidell, L. (2001). Using multivariate statistics ( $4^{\text {th }}$ ed.). San Francisco, CA: Allyn and Bacon.

Treviño, L. K., Butterfield, K., \& McCabe, D. (1998). The ethical context in organizations: Influences on employee attitudes and behaviors. Business Ethics Quarterly, 8(3), 447-476. doi: $10.2307 / 3857431$

Treviño, L. K., den Nieuwenboer, N. A., \& Kish-Gephart, J. J. (2014). (Un)Ethical behavior in organizations. Annual Review of Psychology, 65, 635-660. doi:10.1146/annurevpsych-113011-143745

Treviño, L. K., Weaver, G. R., \& Reynolds, S. J. (2006). Behavioral ethics in organizations: A review. Journal of Management, 32, 951-990. doi:10.1177/0149206306294258

Victor, B., \& Cullen, J. B. (1987). A theory and measure of ethical climate in organizations. In W. C. Frederick, Research in corporate social performance and policy (pp. 51-71). Greenwich, CT: JAI Press.

Victor, B., \& Cullen, J. B. (1988). The organizational bases of ethical work climates. Administrative Science Quarterly, 33, 101-125. doi: $10.2307 / 2392857$

Williams, B. (1985). Ethics and the limits of philosophy. Cambridge, MA: Harvard University Press. 